\title{
Self-reliant India: self of a nation or a national self?
}

\author{
Sundar Sarukkai ${ }^{1}$
}

Accepted: 18 September 2020 / Published online: 2 November 2020

(c) Institute for Social and Economic Change 2020

\begin{abstract}
The pandemic has led to a renewed reflection on what it means to be self-reliant in terms of our everyday practices. Nations too follow this logic in their own claims of self-reliance. This paper discusses the implications in these claims of self-reliance in the context of the nation by positioning this claim within the tension between two different formulations of the self: self of the nation as against the idea of national self.
\end{abstract}

Keywords Self $\cdot$ Social $\cdot$ Individual $\cdot$ We-self $\cdot$ Nation $\cdot$ Swaraj

Although there is an increased push for self-reliance globally these days, the idea of being self-reliant is a long one. The relationship between the independence movement and selfrule is an expression of political self-reliance. The latest invocation of self-reliance by governments in India and elsewhere is primarily about economic self-reliance but like in the Indian case it is more specifically about self-reliance in manufacturing. But the nature of self-reliance is such that it is difficult to understand economic self-reliance without other forms of self-reliance, most importantly, a self-reliance of the 'self' as well as of the 'intellect'. It is this range of ideas that are present in self-reliance that needs to be understood, even for the narrow vision of self-reliance in manufacturing or other economic processes. In the context of the self-reliance of the nation, there is a new conceptual challenge that we have to face, namely, the use of the term self in the context of the nation. What work does the term 'self' do in the articulation of self-reliance of a nation? How does the nation get or possess a self, since the self is most commonly seen as the attribute of individuals? Does this imply that the nation gets unified as an individual even though the nation is a collection of individuals? And does the association of self to the nation lead to contradictions for a democratic nation?

In this essay, I want to explore the notion of self-reliance in the context of the nation in a very limited way. On the one hand, the term 'self-reliance' needs little philosophical reflection since its meanings are seemingly apparent. In fact, in our common usage of this term, the word 'self' plays very little part. It primarily functions in terms of insideoutside: self-reliance means nothing more than not to be reliant on the outside (others) but even this simple meaning has deep assumptions about inside-outside, self-other

Sundar Sarukkai

sarukkai1@yahoo.com

1 Bangalore, India 
and so on. While this is a common usage of this term, in this essay I want to argue that there is a hidden function of the many meanings related to the self. These multiple approaches and paradoxes about the self arise in the many different questions about self-reliance. There are many different ways to understand the meaning of 'self', ranging from the ontological to the narratological. I do not want to enter into these different formulations but will focus on one implication of invoking the self in a term that has pragmatic considerations for the functions of a nation. I begin with some reflections on the question of the self during COVID. What I say here are some preliminary remarks to motivate the reason for critically focussing on the meaning of self in self-reliance. Then I try and attempt to understand why the notion of the self (which is so much related to the individual) is invoked in the context of the nation. What is in the understanding of a nation that allows the possibility of linking the nation to a self? I suggest that there are two primary ways of understanding the meaning of a self in relation to the nation: self of a nation and a national self. The implications of these two formulations are quite distinct and have differing implications on the meaning of self-reliance.

The COVID-19 pandemic has created a special problem that has to do with the relationship between the self and the society. The social pre-COVID was a field which catered to individual interests - from security, health, infrastructure and travel to shopping. What the pandemic really destroyed was our access to the social world, a world in which others performed their work on behalf of others. Labour itself was oriented around this act of distributing the tasks that one had to do for oneself. Restaurants took care of the individual's need for cooking one's own food, schools took care of the children (at least for a major part of the day), hospitals took control of health (much of which could have been in the hands of individuals themselves) and so on. Pre-COVID we were a society that increasingly developed a sense of the social defined through dependency. That was not a social that came together through friendship or kinship or as members working towards a common goal. The society itself was moving more and more towards not just a service economy but a service society, where the very idea of the social was reduced to a system designed to take care of the interests of individuals. Shopping malls were a literal exemplification of this social in urban areas.

Technology plays a major role in this subordination of the individual to the society since the basic functions of the individual were outsourced to technology. Right from the beginning, the ideal of technology was to replace manual labour-labour characterized as routine, as a drudgery and not having sufficient value. Thus, labour associated with hard physical work was slowly replaced by machines and household labour by women was taken up by technologies such as the washing machine. The aim of this view of technology was that eventually all human actions-particularly those that were repetitive and monotonouscould be completely outsourced to machines. This view of technology has become so much a part of our very understanding of a society that the great chess player, Gary Kasparov (2017), in his book Deep Thinking extends the promise of new digital technologies by arguing that now they can take care of 'menial' mental tasks which includes the human capabilities of memory, recall, calculating and so on. Technology became an important part of the society in that it made possible the worldview that saw the social world as a world which was there to take care of, protect and more increasingly entertain individuals. In this view of society, not just the government but also other people in a society had become like technology-they were all cogs who took care of one or the other of the jobs to support the interests and desires of the individual. The fact that any social based on this utilitarian end is inherently hierarchical only meant that this form of the social was always geared towards protecting the interests and desires of the more privileged. 
The pandemic rudely halted this unquestioned function of society. It first squeezed off the subletting of individual action to others. People who did not know the basics of cooking had to learn them. Those who saw shopping as a social interaction found that the most taken for granted liberty - the 'right' to shop-was suddenly removed. There were no gyms for exercise and one had to find ways to exercise by oneself in the confines of their house or in the restricted space of their apartment blocks. Social distancing literally distanced the social from each other's lives. The claim that this was not really social distancing but only physical distancing misses the point about the impact of the presence of individuals in the creation of the social. The anonymous and virtual social of social media, mediated through digital technology, was just a two-dimensional caricature of the real social that characterizes human relations. This phenomenon is not new and can be seen occurring repeatedly in discussions on the idea of 'presence' in theatre in contrast to films, for example.

But just as the social was being distanced, there was a concomitant discovery of the individual and a revival of that worn-out cliche, 'discovering oneself'. It was as much a discovery of what one could do by oneself, tasks which were originally expected to be done by others-whether it was laundry, ironing one's clothes, carrying out garbage and for a lot of people just sweeping and mopping. Many of these chores were not easy but at least it became clear why they were not easy. I do not believe that we will learn lessons from this forced reallocation of labour practices, which ideally should make us respect the people who do these jobs for us more than before. Once the situation normalizes, we will go back into the surrogate world of the social but at least now we are forced to confront how much of the individual self has been mortgaged to others in the name of labour and service.

What does this re-discovery of the self imply for the future ideas of the social? It is quite instructive to see what has happened to the hospital services during this time. Hospitals which were full of patients seeking treatment for something or the other suddenly found that many who would have otherwise landed up for consultation preferred to wait or depend on home remedies. Although the COVID has had some negative impact on those who needed urgent medical intervention, overall the number of people who discovered individual practices to help them fight their problems increased. This was one direct mode of the strengthening of the individual and this included changes in lifestyle practices including exercising, control over food, etc. In other words, the pandemic allowed us a chance to rethink what it means to be self-reliant with respect to our own selves.

However, the meaning of being self-reliant depended to a large extent on the modes of the discovery of the self as described above. While it might seem that the examples above point to a 'strengthening' of the self, it is not necessarily the case. I used these examples only to show how a re-organization of our everyday understanding of the self happened through these responses to the COVID situation. As I also mentioned above, these new examples of self-reliance came in response to the prior situation of our society functioning largely as a 'service society' as well as the deeply social nature of individual lives in places like India. One could also argue that the COVID situation actually created more selfishness and antisocial tendencies in our society leading to important ethical problems. ${ }^{1}$ What these tendencies point to is the confusion in the meaning of self-reliance. In the examples discussed above, we can note the processes of strengthening the self and also becoming more selfish. But how do these qualities affect the question of reliance, being reliant upon? What I would argue is that the very notion of reliance implies the social and self-reliance is only

\footnotetext{
1 I thank a reviewer of this essay for pointing this out.
} 
about strengthening the self as a social actor whereas being selfish is relying on the self in a world of just that self. In a similar analogy, we can think of self-reliance of a nation as being totally inward looking and acting as if other nations do not exist or we can consider it as acknowledging that the nation is part of a global system and yet is able to be selfsustaining. Thus, while the COVID period has led to selfish practices there has also been the possibility of expanding one's own awareness of the self in relation to relying on others.

\section{Self, individuals and the nation}

What happens to us as individuals happens to nations also. 'Make in India' was already a saleable slogan. Trump had further legitimized such slogans through his own version of 'Make in America'. Make in became a new slogan of legitimate nationalism. The pandemic, as much as it shone a spotlight on the social dependency of individuals, also made nations realize how much they depended on other nations. The global was always a lot like the social - it was not really based on notions of friendship, ideas of kinship or a sensitivity to the common humanity but was more utilitarian and driven by dependencies. Suddenly we realized that in the great story of Indian pharma producing cheap drugs, there was another story of dependence on China for a major part of the raw material for these drugs. The finance sector is anyway so globally wired that the very idea of strengthening the nation like strengthening the individual would be a non-starter. The market economy drives so much of the idea of the global that in spite of market crashes few are worried as they all realize that the world we have created is not possible if the market dependencies are over.

However, as I argued earlier, the pandemic also revived more strongly the spirit of individual self-reliance as against individualism as a social practice. This recognition of the possibility of individual strength is also a model for the revival of the strength of a nation. And the most powerful example of the strength of the nation-in the model of the individual-lies in the 'self-reliance' of a country.

But what is the meaning of the self here? Why invoke the idea of self-reliance of a nation when the very idea of the self of an individual is itself so complicated? What task does the term 'self' perform in these articulations?

We can begin with the reasons why the self is invoked in the context of the individual. What role does the 'self' perform in the case of individuals? Why do we even invoke this term? I will not enter into a debate on whether we should make an ontological commitment to the self but only discuss the reasons why we tend to invoke the notion of the self. The self helps us make sense of some of the experiences we have such as the feeling that experiences happen to 'me'. The use of the notions of me, mine and myself are indicators of the action of a self. Thus, self marks the basic identity that one has of who they are. But there are also other important reasons for our naive invocation of the self: unity of the senses that is presupposed in the belief that different experiences (such as seeing, hearing, touching, etc.,) all happen to the 'same me', that all experiences over time (from the time we are born) happen to the 'same me' and so on (Bhatt 1962). The self generates a notion of the unity of the experiences that are part of our lives and gives us a sense of identity. It gives us a sense of 'ownership' over our experiences (Guru and Sarukkai 2012). It helps us to understand the nature of human action and human agency, such as the question 'who' is acting. We could go to the extent of saying that the basic notions of the unity presupposed in an object is one that is modelled on the self. An object is nothing more than a collection 
of different qualities, such as colour, shape, size and taste. So, what is the object other than these qualities? How do these qualities all belong to 'one' object? This cognitive inclination to unify diverse qualities in one is common to our basic recognition of objects (and therefore the world) and the self.

We talk about the social in pretty much the same way (Guru and Sarukkai 2019). We use terms like 'we' and the 'we-self' just like we talk about I and the I-self. We belong to a social in ways similar to that in which different experiences belong to the same individual. The very idea of a nation with concomitant ideas such as 'belonging to the nation' is based on these beliefs about the self. So, it is not a surprise when the nation repeatedly invokes ideas of self-rule and self-reliance for these are all assertions of the self.

There is an important characteristic of the sense of unity which is an essential element of the notion of the self. An individual has a wide variety of experiences. This diversity of experiences, some of which may be pleasant but some undesirable like experiences of sickness or sadness, are all unified, however diverse they are. The unification that is the core of the idea of the self is not a unification based on reducing all the experiences to an idea of sameness. Rather, the unity is one that is based on the idea of the self as the substratum of all experiences. All experiences that we have are unified not because these senses have common elements but because they are all 'located in oneself'. This idea of unity is extremely important when we talk about the self of the nation.

The nation is most fundamentally defined by a sense of unity and identity. The nation borrows its vocabulary of belongingness from the notions of a self. But this is of a social self and not the individual self. A social self adds an important component to a forgotten aspect of the individual self. This is the aspect of responsibility to others who are part of the social self. For traditions which have engaged deeply with the question of the individual self, there is a sense of self-responsibility which is extremely important. The individual self experiences but also regulates itself. (This can be contrasted to the culture of 'me and mine' that is a particular understanding of the self where there are no questions of selfresponsibility.) In the case of a social self like the nation, the regulatory aspect becomes most problematical since it raises a question of who is going to regulate the actions made on behalf of the nation, the socialized self.

The concept of the nation has always had a parasitic dependence on the notion of the self. In the independence movement, it is most prevalent in the debate on self-rule. The idea of self-rule is self-explanatory: in both these terms which use the word self, the meaning of the self is in opposition to the outside(r). Self-explanatory means that there are no external requirements to understand an expression and self-rule is about the capacity to rule one selves without the assistance of the outsider. (It is important not to conflate the outsider and the other in this context.) The idea of self-rule is an essential component of any notion of the nation since the nation, by definition, gets defined with respect to the insider-outsider dichotomy.

Gandhi's understanding of self-rule illustrates the need for invoking the idea of self in the context of the nation. One of his most influential works, Hind Swaraj, is a handbook for self-rule as indicated in the title itself. The list of terms that work around the idea of the self become defining elements of the independence movement: terms such as swaraj, swadeshi, swabhiman. The reason that self or the prefix swa is so important to these articulations is because within the idea of self there is a notion of both freedom and governance. The self is an excellent example of responsibility with freedom since the self will indulge in what it wants but has a core of survival within it-what we refer to as self-preservation. The fight against the British is not captured merely by the word 'independence'. The Indian language connotations for this word include swatantra and swavalamban, both of which 
have an explicit grounding in the self. This necessary connection with swa locates the principal idea of independence within the self first and thus all invocations of swaraj by Gandhi and other leaders have to be understood not just as liberation from the British but as an essential practice related to freedom and responsibility of the self.

An important addition to this debate comes through the tension between Gandhi and Ambedkar. Nagaraj (2012) captures this tension through the invocation of two terms derived from the self: self-rule versus self-respect. The distinction between these two terms has a significant impact on the very definition of freedom and its relation to the self. Selfreliance (and the expressions of make-in) in the context of the nation has elements both of self-rule and a strong dose of self-respect. Much of India's rhetoric on self-reliance (especially the Make in India kind) is a call for self-respect within a hierarchy where India is placed low in the order. Self-reliance in this context is not self-rule but only about assertions of self-respect.

Self-reliance is closely related to the ideas of swaraj. It is a reaffirmation of the idea that ruling itself has to be from within and by oneself. One is free and accountable to that freedom at the same time. Much depends on what we mean by the self here. For Gandhi, ruling oneself meant disciplining the self and that includes the responsibility of the (individual) self. Being self-reliant does not mean asociality but only the responsibility of oneself for oneself. But how is it possible to be self-reliant? What are we supposed to be self-reliant about? These questions become important in the context of the self-reliance of a nation. We can glimpse the contours of this question in the philosopher K. C. Bhattarcharyya's (KCB) essay 'Swaraj in ideas' (Bhattacharya 1984). This was an essay which has been understood in different ways but the fundamental question that Bhattacharya poses is the possibility of thinking about our society in ways that do not draw upon the 'outsider'. He suggests that the foreigner cannot understand the Indian society like 'we' do and that drawing upon the resources of the society might offer a better understanding of the society. As Raju (2017) points out, KCB should be seen as responding to the crisis of organic thinking and organic solutions to the problems of our society. Independence is not limited to political independence but also needs the independence of the mind. The independence of the mind can only be supported by a self that is self-confident, that can feel secure in the foundations of its philosophies and experiences. There can be no swaraj without swaraj in ideas, in worldviews, in projecting the future which we want and not based on the interest of 'outsiders'. It is as much a question of self-articulation of who we are and what our vision of the world will be. While there are many points which may be debated in this view, it is nevertheless an important theme that will arise in any claim of self-reliance. Perhaps the most important point in this idea of self-articulation is the problem of articulating on behalf of others who constitute the 'us' and 'we'. Who is going to speak on behalf of a group, a community, a society, a nation? What kind of a social self will be allowed by the individuals to speak on their behalf? Nation is one of the most powerful illustration of the action of a social self and thus the meaning of a nation becomes as complex as that of the individual and social self. 


\section{Self of a nation and national self}

I believe that there are two functions of the term 'self' in the context of the nation: one referring to the 'self of a nation' and the other to 'national self'. The difference between these formulations is quite stark and impacts the way we understand self-reliance in the context of the nation.

When references are made to the self of a nation, it is primarily about the qualities of the nation related to the themes of identity, belongingness and the space of experiences for those who live and/or belong to it. In this sense, it is analogous to, and possibly modelled on, how one understands articulations of oneself. On the other hand, the national self does not refer to the nation at all but is more a reference to some quality of the individual selves. It is a quality of the members of that nation and is not really about the self of a nation per se.

Depending on the meanings we ascribe to self, we can discover different meanings for self-reliance in the context of the nation. Why would we even invoke the notion of self in the context of the nation? What can accommodate a meaningful understanding of the self when it is used in the context of the nation? At a pragmatic level, it is easy to see why the invocation of self is 'natural' for a nation: we refer to a nation as 'my' nation and so concepts of my, mine, mineness and related issues of identity arise for the nation in a way similar to that of the experiences of the individual self. But at the same time, the self related to the nation also refers to a we-self, a self of a larger social. It is also an embodied social and this quality makes it different from other social selves. Just as the individual self is embodied in the physical body, the self in relation to the nation is embodied in the physical nation, with its geographies and boundaries. But it is also precisely because of these characteristics, that the self in the context of a nation has to accommodate plurality, diversity. This quality again distinguishes the self of the nation from other social selves related to gender, caste and religion, for example. This self which can accommodate plurality and difference is one that functions as a substratum and does not insist on sameness. It is the quality of ashraya - a shelter for the multiple, diverse individuals, practices and traditions. The self of a nation is this true shelter, the foundational substratum where unity is possible only because of a sense of feeling that it is happening to all of us.

However, this is not the only notion of a self that is possible in the context of the nation. There is also another possibility, one that is often imposed on individuals. The nationinstead of being seen as a collective social — can be reduced to a quality of the individual. In this case, it is not a self that stands 'outside' the individual. A self which incorporates the nation within itself is a national self and thus is one quality of a self, a quality that is hegemonic and imposed. It arises through the cognitive act of an individual and is most often not directly related to their experiences. But the power of the (internal) national self as against the (external) self of the nation is that it evokes deep emotions within the individual. The self of the nation is a recognition of a more complex, plural self that operates outside the individual but yet one in which the individual is part of. Whereas the national self incorporates the nation within the self and thus creates a sense that the nation belongs to 'me'. So, when certain individuals start speaking on behalf of the nation-what the nation should be like, what people living in that nation should do and should not do-they are illustrating the functioning of the national self. Nationalism in its most troublesome form arises through the formation of a national self.

These are not merely some abstract formulations about the self and the nation. These notions of the self are invoked in the rhetoric of self-reliance and my argument is that the 
two different meanings of the self in relation to the nation create different meanings for 'self-reliance'. If the meaning of self in the expression 'self-reliance of the nation' is referring to the 'self of the nation', then self-reliance cannot be just about producing what we need for the citizens of this country. It also means a discipline of the self of the people in the country, and this is a civilizational and axiological task. It is about values in a society and not material production. These qualities, taken, for example, from Gandhi, Tagore and others, would imply a very different meaning of the nation where the nation is not one which is homogenized, is violent, is hierarchical, is non-egalitarian, is consumerist and so on. As Parel (2000) points out, Gandhi's formulation of self-rule had four components, three related to independence of the nation, economic freedom and political freedom but the essential fourth component was self-rule, here seen as the rule of the individual self by the individual self. This self-rule included the important quality of self-control including control of the body and the desires of the senses, control over thinking and so on (Banerjee 2020).

Why should this difference matter? It matters because these two versions of the self/ nation relation have implications for the meaning of self-reliance. What does it mean to be self-reliant? The simplest answer is to be independent of others. But what is the independence from others that we are seeking? The nation can be independent from others in the products it produces, in its economy, in its policies and so on. But this does not really encompass the many meanings of swaraj that we talk about. As KCB points out, it is equally important to have swaraj in ideas, a freedom in the intellectual domain. Are we anywhere close to having the freedom in the intellectual domain? We do not even produce knowledge and worldviews which matter to the rest of the world. It does not seem to matter to our own intellectuals and students. What are the ideas that drive the nation? Where are the ideas being produced? How democratic is this source of ideas? Is it able to include the visions and aspirations of not just the 'intellectual community' but also the everyday experiences of diverse communities in India? This is not a question about geographical origins but about philosophical origins. What kind of views about the nature of society, family, individuals should matter to us today when we imagine the future of the nation? The answer is not in the geographical 'outside' or the cultural 'inside'. It is not going to come from the 'west' or from the 'past' alone. The self-reliance that the government talks about is about factory goods but without the swaraj in ideas none of these are self-sustaining.

Self-reliance is not in manufacturing alone. It has to be the articulation of the self of a nation about progress and development, about educational goals for the future citizens of the country, about basic well-being of all the citizens particularly the dispossessed and the marginalised. What we need to 'Make in India' are civilizational values, our own articulations of the idea of equality in an unequal society, a democracy that functions effectively, and anything else which can lead to a truly free, democratic and egalitarian society. To 'make' all this in a self-reliant manner is the true idea of a nation and the true self of a nation. The easier task is to reduce the self of a nation to one idea of a national self is but this is also the more dangerous. The national self is an individual self which understands the national as one quality of the individual self. But a nation cannot be a quality of a self because it reduces the nation to the interests of individuals. In such a case, the nation as such cannot acquire a unified self just because all the people in the country possess one national self. The self of a nation is one that is self-reliant in the true sense of the term, one that is truly independent.

Acknowledgements I thank the two referees for their insightful and critical comments which have helped me clarify some points in this essay. 


\section{References}

Banerjee S (2020) Tracing Gandhi: Satyarthi to Satyagrahi. Routledge, London Bhatt GP (1962) The basic ways of knowing. Motilal Banarsidass, Delhi

Bhattacharyya KC (1984) Svaraj in Ideas. Indian Philos Q 11(4):461

Guru G, Sarukkai S (2012) The cracked mirror: an indian debate on experience and theory. Oxford University Press, Delhi

Guru G, Sarukkai S (2019) Experience, caste and the everyday social. Oxford University Press, Delhi

Kasparov G (2017) Deep thinking. Where machine intelligence ends and human creativity begins. Hatchette India, Delhi

Nagaraj DR (2012) The flaming feet and other essays. Orient Blackswan, Delhi

Parel A (ed) (2000) Gandhi, freedom, and self-rule. Lexington Books, New York

Raghuramaraju A (2017) Modern frames and premodern themes in Indian philosophy. Routledge, London

Publisher's Note Springer Nature remains neutral with regard to jurisdictional claims in published maps and institutional affiliations. 